\title{
Solid-State Joining of Ultrahigh Carbon Steels
}

\author{
A. J. Sunwoo
}

April 22, 1993

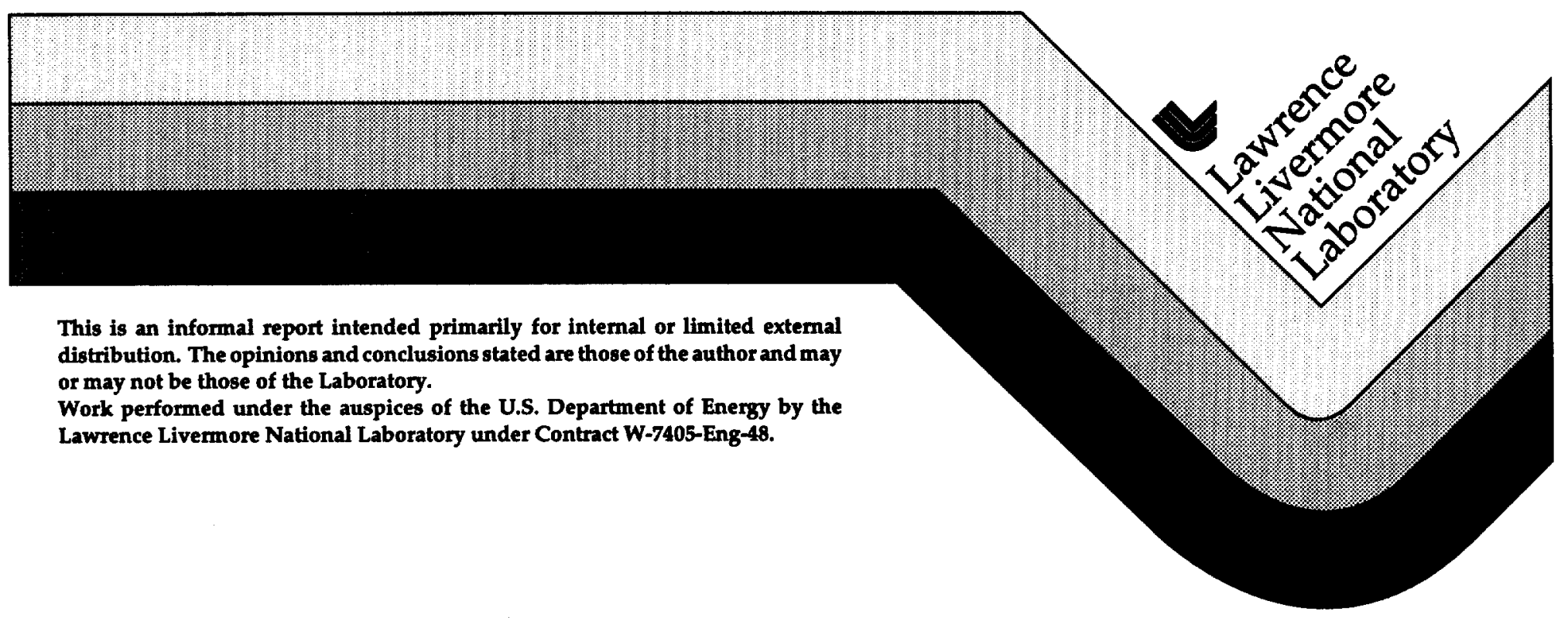




\section{DISCLAIMER}

This document was prepared as an account of work sponsored by an agency of the United States Government. Neither the United States Government nor the University of California nor any of their employees, makes any warranty, express or implied, or assumes any legal liability or responsibility for the accuracy, completeness, or usefulness of any information, apparatus, product, or process disclosed, or represents that its use would not infringe privately owned rights. Reference herein to any specific commercial product, process, or service by trade name, trademark, manufacturer, or otherwise, does not necessarily constitute or imply its endorsement, recommendation, or favoring by the United States Government or the University of California. The views and opinions of authors expressed herein do not necessarily state or reflect those of the United States Government or the University of California, and shall not be used for advertising or product endorsement purposes.

This report has been reproduced directly from the best available copy.

Available to DOE and DOE contractors from the Office of Scientific and Technical Information

P.O. Box 62, Oak Ridge, TN 37831

Prices available from (615) 576-8401, FTS 626-8401

Available to the public from the

National Technical Information Service

U.S. Department of Commerce

5285 Port Royal Rd.,

Springfield, VA 22161 


\title{
Solid-State Joining of Ultrahigh Carbon Steels
}

Anne J. Sunwoo

\begin{abstract}
A joining study of these steels was initiated to determine the feasibility of using ultrahigh carbon steels in structural applications. The high carbon content $(1.5 \mathrm{wt} \%)$ in these steels and the desire to maintain the superplastic microstructure limit the use of conventional arc-welding processes. We chose two solid-state joining processes: diffusion bonding and inertia friction welding. Preliminary results show that sound bonds can be obtained with tensile properties nearly equal to those of the base metal. Of three UHC steels bonded by both inertia-friction welding and diffusion-bonding processes, the one with the lowest aluminum content had the best overall properties. Diffusion bonding with a nickel interlayer showed the most promising results for the UHC steel containing $1.6 \mathrm{wt} \%$ aluminum. The properties of inertia-friction-welded steels can be improved by a post-weld heat treatment.
\end{abstract}




\section{INTRODUCTION}

Ultrahigh carbon steels are hypereutectoid steels in which, through extensive thermomechanical processing, very fine carbide particles $(0.1-0.5 \mu \mathrm{m}$ in diameter) in a finegrained ferrite matrix $(0.5-1.0 \mu \mathrm{m}$ in diameter) can be developed. With this tailored microstructure, UHC steels display superplastic (SP) behavior ${ }^{1-4}$ and also exhibit good roomtemperature mechanical properties. ${ }^{4,5}$ To investigate the feasibility of using these steels in structural applications, a joining study of these steels was initiated. The high carbon content in these steels and the desire to maintain the SP microstructure limit the use of conventional arcwelding processes. Earlier work by Sherby et al. ${ }^{6}$ has shown success with a press-bonding technique to join both similar and dissimilar steels.

In this study, we chose two solid-state joining processes: diffusion bonding (DB) and inertia friction welding (IFW). Each process has advantages and disadvantages.

With DB, the integrity of the components is maintained because the process uses the solidstate diffusion mechanism. Hence, joints can be produced with the microstructure and mechanical properties comparable to those of the parent metal. The DB components undergo minimum distortion and have low residual stresses.

The major disadvantage of DB is surface oxide, which prevents metal-to-metal contact by acting as an insulating layer. In an unprotected environment, all metals tend to form surface oxides, some more stable and tenacious than others. To change the surface chemistry, a diffusion interlayer is often used. Ideally, at the bonding temperature, the interlayer diffuses into the substrates, leaving clean surfaces to establish an intimate metal-to-metal contact. Another factor that influences DB integrity is surface roughness. Two kinds of surface roughness are present at the mating surfaces: long-wavelength and short-wavelength asperities. Pressure applied during the initial stage of bonding reduces the height of long-wavelength asperities. Pressure applied in conjunction with an interlayer (the softer the interlayer, the less pressure required) also reduces porosity at the bond line by filling the voids of short-wavelength asperities. ${ }^{7}$ With sufficient time at bonding temperature, interdiffusion of the interlayer elements and of the solutes from the substrates leaves an undetectable bonded interface.

With IFW, surface chemistry and roughness are not controlling factors in producing a sound weld. In this process, two specimens are joined by a mechanically induced rubbing motion at the joining surfaces. As the surfaces heat up, an axial force is applied to create an upset, displacing the previously existing surface oxide and providing a clean interface for welding. This is a rapid process with a significantly shorter time at elevated temperatures than in DB. However, because of the localized heating and forces, a heat and deformation zone (HDZ) is created in the bond area, 8,9 and the resulting microstructural changes degrade the mechanical properties of temperature-sensitive materials. 
The purpose of this work is to determine the feasibility of joining UHC steels using the DB and IFW processes.

\section{EXPERIMENTAL PROCEDURES}

Table 1 lists the analyzed compositions of three as-received UHC steels. The IFW parameters used were the same for all three steels. The IFW specimens were 9.5-mm (0.375-in.)diameter rods. One specimen was held stationary while the other was rotated at $2500 \mathrm{rpm}$, and a weld pressure of $3.49 \mathrm{MPa}$ (500 psi) was applied until a $2.45-\mathrm{mm}(0.095$-in.) upset was achieved. Subsequently, a forge pressure of $7.68 \mathrm{MPa}$ (1100 psi) and a brake were applied simultaneously to provide an additional torque.

The DB study was designed to evaluate the effects of different surface compositions and coating processes on the quality of the bond: sputter-cleaned surface vs silver or nickel interlayers with either electroplating or physical-vapor-deposition (PVD) coating processes. The surfaces to be bonded were dry-machined to a $0.8-\mathrm{mm}(0.032$-in.) finish. The thickness of the interlayers used depended on the coating processes. Using PVD, we coated only silver to a thickness of $\sim 10 \mu \mathrm{m}$, whereas we electroplated both silver and nickel to a thickness of $\sim 25 \mu \mathrm{m}$. We used conventional PVD and electroplating procedures to clean and coat the surfaces. For all surface conditions, we performed DB under a $10^{-7}$ torr vacuum for one hour, applying different pressures and temperatures for the different surfaces (see Table 2).

We performed tensile tests on an electromechanical, screw-driven Instron test machine with a capacity of $89.6 \times 10^{3} \mathrm{~N}$ (20 kip), using two extensometers to provide the average strain data. All specimens were pulled to failure at room temperature with a crosshead speed of $0.02 \mathrm{~mm} / \mathrm{s}$ (0.05 in./min). For the IFW tensile specimens, the gage length and diameter were $25.4 \mathrm{~mm}$ (1.0 in.) and $6.35 \mathrm{~mm}$ (0.25 in.), respectively, and for the base-metal and DB specimens, the gage length and diameter were $12.7 \mathrm{~mm}(0.5 \mathrm{in}$.) and $4.06 \mathrm{~mm}(0.16 \mathrm{in}$.$) , respectively. The base$ metal microstructure and fracture surfaces were examined with a scanning electron microscope.

\section{RESULTS and DISCUSSION}

\section{Base Metal Microstructure}

The base metal microstructure of S-10 and H-68 in the short-transverse direction is shown in Figure 1. The as-received S-10 was in the hot and warm worked condition, where the steel was thermomechanically processed at temperatures above $\mathrm{A}_{1}, 1150^{\circ} \mathrm{C}$ and $800^{\circ} \mathrm{C}$, respectively. The resulting microstructure of $S-10$ consists of a pearlitic matrix with fine proeutectoid carbides at the prior austenite grains and boundaries (Figure 1a). On the other hand, H-68 was hot worked and austenized above $A_{1}$ to obtain a fully spheroidized structure in place of pearlitic lamellas. The 
resulting microstructure of $\mathrm{H}-68$ contains a uniform bimodal distribution of fine spheroidized carbides in the ferrite matrix and coarse proeutectoid carbides at the boundaries (Figure 1b).

\section{IFW Behavior}

In the IFW specimens, as expected, an HDZ occurred near the weld interface. Vickers microhardness profiles taken across the weld of a polished H-68 specimen (Figure 2a) indicate that the hardness increases within $1 \mathrm{~mm}(0.04 \mathrm{in}$.) of the weld interface from a base value of $\sim 350$ to a maximum of $\sim 500$. Figure $2 b$, an optical micrograph, shows the outer periphery of the welded specimen that corresponds to the hardness profile. Although the micrograph shows an asymmetrical flow of the material, which could result from a low axial force, the hardness profile is symmetrical. Further, the micrograph shows a fine crack at the welded area (region A-A), suggesting that the weld could be incomplete.

Table 3 summarizes the tensile test results of both base metals and IFW specimens. The composition of the base metal significantly influenced the properties of UHC steels in both welded and unwelded conditions.

The tensile properties of UHC steels show an inverse relationship between strength and ductility. The S-10 base metal had lower strength but higher ductility than the H-68 base metal. The lower ductility of $\mathrm{H}-68$ is attributed to its higher percentage of chromium. About $1.4 \%$ to $1.6 \%$ chromium added to UHC steels has shown to improve both superplastic and roomtemperature properties. ${ }^{2}$ Chromium is known as a carbide stabilizer and has a high solubility in cementite to form a complex carbide ( $\mathrm{Fe}, \mathrm{Cr}){ }_{3} \mathrm{C}$. ${ }^{10}$ During superplastic forming, carbides inhibit the ferrite grain growth by pinning the grain boundaries. At room temperature, fine, equiaxed grains enhance the strength of UHC steel, however, the presence of excessive carbides in the grain boundaries limits its ductility.

Aluminum, like silicon, is a known ferrite stabilizer and raises the $\mathrm{A}_{1}$ temperature of $\mathrm{Fe}-\mathrm{C}$ steels, a condition beneficial to superplastic forming. ${ }^{4}$ Further, aluminum inhibits the precipitation of proeutectoid carbides on cooling from the austenitic region and thereby prevents the formation of carbide network at the boundaries. With high aluminum and chromium contents in H-68, a high volume fraction of carbides that present could lead to its low ductility.

We successfully inertia-welded S-10I specimens, achieving $100 \%$ joint efficiency (i.e., the ratio of the joint yield strength to that of the base metal) with relatively good elongation. The ductility of the joint improved with a post-weld heat treatment at $700^{\circ} \mathrm{C}$ for one hour, which was about $75^{\circ} \mathrm{C}$ below the $A_{1}$ temperature of this steel. The strength of the inertia-welded S-6I specimen was comparable to that of the S-10I specimens, but its ductility was lower, and the $\mathrm{H}$ 68I specimen failed prematurely. This premature failure may be because the same IFW parameters were used for all three steels and were not optimized for the higher strength H-68 steel. Because 
the H-68 base metal is stronger than S-10, a greater axial force is needed to decrease the HDZ.8,9 After post-weld heat treatment, both strength and ductility of the H-68I800 specimen improved remarkably.

Comparison of the fracture surfaces of S-10 base metal and IFW specimens revealed a distinct difference in the fracture mode. The base metal failed in a ductile mode with a uniform distribution of fine dimples (Figure 3a), whereas the as-welded specimens failed with a mixed cleavage-intergranular fracture (Figure $3 \mathrm{~b}$ ). Comparison of the fracture surfaces of S-10I and $\mathrm{H}$ $68 \mathrm{I}$ (Figures $3 \mathrm{~b}$ and $4 \mathrm{~b}$ ), revealed no detectable difference in a fracture mode between these two specimens: both showed a mixed cleavage-intergranular fracture with little deformation. The ductility of the IFW H-68 specimen improved with post-weld heat treatment, and the fracture surface was indicative of this improved ductility (Figure 4a). The fracture surfaces of the post-weld heat-treated S-10 and H-68 specimens became similar to that of the S-10 base metal. This was expected because the post-weld heat treatment should have relieved some of the thermal and stress gradients adjacent to the welded interface.

\section{$D B$ Behavior}

A similar trend is also seen in the tensile properties of DB UHC steels (Table 4). As the aluminum content of the steel increases, strength and ductility decrease regardless of the interlayer composition. Other than the nickel interlayer, many of the bonds failed either during machining or prematurely during testing. Of all the DB specimens, the S-10 with the nickel interlayer had the best overall combination of strength and ductility. The as-bonded properties of $\mathrm{S}-10 \mathrm{Ni}$ are much better than those of the as-welded S-10I.

Adding aluminum to the steels has a considerable influence on the surface chemistry of the bonding interfaces. Aluminum forms a very stable and tenacious oxide and has a low solubility for oxygen. The use of silver interlayer and PVD coating process did not enhance the DB of these steels. In $\mathrm{DB}$ of other metals, silver is a favored interlayer element because $\mathrm{Ag}_{2} \mathrm{O}$ decomposes at $190^{\circ} \mathrm{C}$ and silver dissolves its oxide. ${ }^{11}$ However, in the presence of aluminum, silver forms $\mathrm{Ag}_{2} \mathrm{Al}$ at the aluminum-silver interface. ${ }^{12}$ Because of the intermetallic formation at the bonding interface, the tensile strength of the DB specimens has shown to decrease as much as $60 \%$. With the nickel interlayer, although both iron and nickel form stable oxides, ${ }^{13,14}$ nickel has a high solubility in iron with no intermetallic formation at the DB interface, which appears to promote the DB of the lowest aluminum containing UHC steel (S-10).

The fracture surface of S-10Ni showed debonding at two interfaces: (1) nickel and UHC steel, and (2) nickel and nickel (Figure 5). Debonding at the nickel-nickel interface appeared to be very ductile. With the higher aluminum content in $\mathrm{H}-68$, debonding occurred mostly at the nickelUHC steel interface, and the fracture surface was highly oxidized (Figure 6). Energy-dispersive X- 
ray spectroscopy of the DB H-68 fracture surfaces indicated mostly iron oxide with a small amount of aluminum.

\section{CONCLUSIONS}

Preliminary results show that sound bonds can be obtained with tensile properties nearly equal to those of the base metal. Of three UHC steels bonded by both inertia-friction welding and diffusion-bonding processes, the one with the lowest aluminum content had the best overall properties. Diffusion bonding with a nickel interlayer showed the most promising results for the UHC steel containing $1.6 \mathrm{wt} \%$ aluminum. The properties of inertia-friction-welded steels can be improved by a post-weld heat treatment.

\section{ACKNOWLEDGMENT}

The author would like to thank P.R. Landon and A. Goldberg for their technical advice, and D.E. Hoffman and L.M. Wagner for performing the inertia-friction welding and diffusion bonding, respectively. Work performed under the auspices of the U.S. Department of Energy by the Lawrence Livermore National Laboratory under Contract W-7405-Eng-48. 


\section{REFERENCES}

1. O. D. Sherby, B. Walser, C. M. Young, and E. M. Cady, "Superplastic Ultrahigh Carbon Steels," Scripta Metall. 9, 569-574 (1975).

2. J. Wadsworth, and O. D. Sherby, "Influence of Chromium on Superplasticity in Ultrahigh Carbon Steels," J. Mater. Sci. 13, 2645-2649 (1978).

3. B. Walser and O. D. Sherby, "Mechanical Behavior of Superplastic Ultrahigh Carbon Steels at Elevated Temperature," Metall. Trans. 10A,. 1461-1471 (1979).

4. O. D. Sherby, T. Oyama, D. W. Kum, B. Walser, and J. Wadsworth, "Ultrahigh Carbon Steels," J. Metals 37, 50-56 (1985).

5. H. Sunada, J. Wadsworth, J. Lin, and O. D. Sherby, "Mechanical Properties and Microstructure of Heat-Treated Ultrahigh Carbon Steels," Mater. Sci. Eng. 38, 35-40 (1979).

6. O. D. Sherby, J. Wadsworth, R. D. Caligiuri, L. E. Eiselstein, B. C. Snyder, and R. T. Whalen, "Superplastic Bonding of Ferrous Laminates," Scripta Metall. 13, 941-946 (1979).

7. G. Garmong, N. E. Paton, and A. S. Argon, "Attainment of Full Interfacial Contact During Diffusion Bonding," Metall. Trans. 6A, 1269-1279 (1975).

8. H. H. Koo and W. A. Baeslack III, "Friction Welding of a Rapidly Solidified Al-Fe-V-Si Alloy," Weld. J. 71, 147s-169s (1992).

9. G. P. Rajamani, M. S. Shunmugam, and K. P. Rao, "Parameter Optimization and Properties of Friction Welded Quenched and Tempered Steel," Weld. J. 71, 225s-230s (1992).

10. C. A. Stickels, "Carbide Refining Heat Treatments for 52100 Bearing Steels," Metall. Trans. 5, 865-875 (1974).

11. J.W. Dini, W.K. Kelley, W.C. Cowden, and E.M. Lopez, "Use of Electrodeposited Silver as an Aid in Diffusion Welding," Weld. J, 63, 26s-34s (1984).

12. P.D. Calderon, D.R. Walmsley, and Z.A. Munir, "An Investigation of Diffusion Welding of Pure and Alloyed Aluminum to Type 316 Stainless Steel," Weld. J, 64, 104s-112s (1985).

13. Z.A. Munir, "A Theoretical Analysis of the Stability of Surface Oxides During Diffusion Welding of Metals," Weld. J, 63, 333s-336s (1983).

14. W.A. Bryant, "A Method for Specifying Hot Isostatic Pressure Welding Parameters," Weld. J. 54, 433s-435s (1975). 
Table 1. Alloy composition of UHC steels, in wt\%.

\begin{tabular}{lllll}
\hline & C & Al & Cr & Mn \\
\hline S-10 & 1.5 & 1.6 & 1.5 & 0.5 \\
S-6 & 1.14 & 3.1 & 1.5 & 0.5 \\
H-68 & 1.5 & 7.7 & 5 & 0.5 \\
\hline
\end{tabular}

Table 2. Diffusion-bonding parameters.

\begin{tabular}{llccc}
\hline Specimens & \multicolumn{1}{c}{ Interlayer } & $\begin{array}{c}\text { Pressure } \\
(\mathrm{ksi})\end{array}$ & $\begin{array}{c}\text { Temperature } \\
\left({ }^{\circ} \mathrm{C}\right)\end{array}$ & $\begin{array}{c}\text { Time } \\
(\mathrm{min})\end{array}$ \\
\hline S-10, S-6, H-68 & Electroplate-Ag & 30 & 500 & 60 \\
S-10, S-6, H-68 & PVD-Ag & 15 & 350 & 60 \\
S-10, S-6 & & Start 30, hold 9 & & \\
H-68 & Electroplate-Ni & Hold $15 @$ @-68 & 600 & 60 \\
S-10 & & & 675 & \\
S-6 & Sputter etched & Start 30, hold 9 & 700 & 60 \\
H-68 & & & 725 & \\
\hline
\end{tabular}

Table 3. Mechanical properties of UHC steels: inertia-welded, and inertiawelded-and-heat-treated specimens.

\begin{tabular}{lccc}
\hline Yield strength & $\begin{array}{c}\text { Ultimate tensile } \\
\text { strength } \\
(\mathrm{kssi})\end{array}$ & $\begin{array}{c}\text { Elongation } \\
(\%)\end{array}$ \\
\hline S-10BM & 138 & 182 & 7.8 \\
S-10I & 140 & 152.5 & 1.22 \\
S-101700 & 130 & 160 & 5.7 \\
S-6I & 126.5 & 160.3 & 0.8 \\
S-6I725b & - & 97.6 & 0.01 \\
H-68BM & 165 & 197.6 & 2.2 \\
H-68Ib & - & 107.1 & 0.01 \\
H-68I800 & 96 & 170.1 & 5.6 \\
\hline a BM and I indicate base metal and inertia-friction weld; 700, 725, and \\
800 are heat-treatment temperatures ( ${ }^{\circ}$ C). \\
b The specimen failed prematurely.
\end{tabular}


Table 4. Diffusion-bonded properties of UHC steels. a

\begin{tabular}{lccc}
\hline $\begin{array}{c}\text { Specimen } \\
\text { preparation }\end{array}$ & $\begin{array}{c}\text { Yield strength } \\
(\mathbf{k s i})\end{array}$ & $\begin{array}{c}\text { Uitimate tensile } \\
\text { strength } \\
(\mathbf{k s i})\end{array}$ & $\begin{array}{c}\text { Elongation } \\
(\%)\end{array}$ \\
\hline S-10: Ni electroplated & $126 / 133 / 129$ & $154 / 171 / 162.5$ & $3 / 6 / 4.5$ \\
S-6: Ni electroplated & $-/ 96$ & $93 / 142 / 117.5$ & $0.7 / 1.5 / 2.8$ \\
H-68: Ni electroplated & & $45 / 41 / 43$ & \\
S-10: Ag electroplated & & $36 / 60 / 48$ & \\
H-68: Ag electroplatedb & & 25.5 & \\
S-10: sputter cleaned $^{b}$ & & $38 / 55 / 46.5$ & \\
S-6: sputter cleaned $^{b}$ & & $31 / 33 / 32$ & \\
\hline
\end{tabular}

a Numbers underlined are average values.

b The specimen failed prematurely. 


\section{Figure Captions}

Figure 1. SEM micrographs showing the base metal microstructure in the short-transverse direction: (a) S-10, (b) H-68.

Figure 2. (a) Hardness profile of $\mathrm{H}-68 \mathrm{I}$ weldment, (b) corresponding micrograph.

Figure 3. Fracture surfaces: (a) S-10 base metal, (b) S-10I.

Figure 4. Fracture surfaces: (a) H-68I800, (b) H-68I.

Figure 5. Fracture surface of S-10 DB with nickel interlayer: (a) low magnification, (b) high magnification.

Figure 6. Fracture surface of $\mathrm{H}-68 \mathrm{DB}$ with nickel interlayer: (a) low magnification, (b) high magnification. 

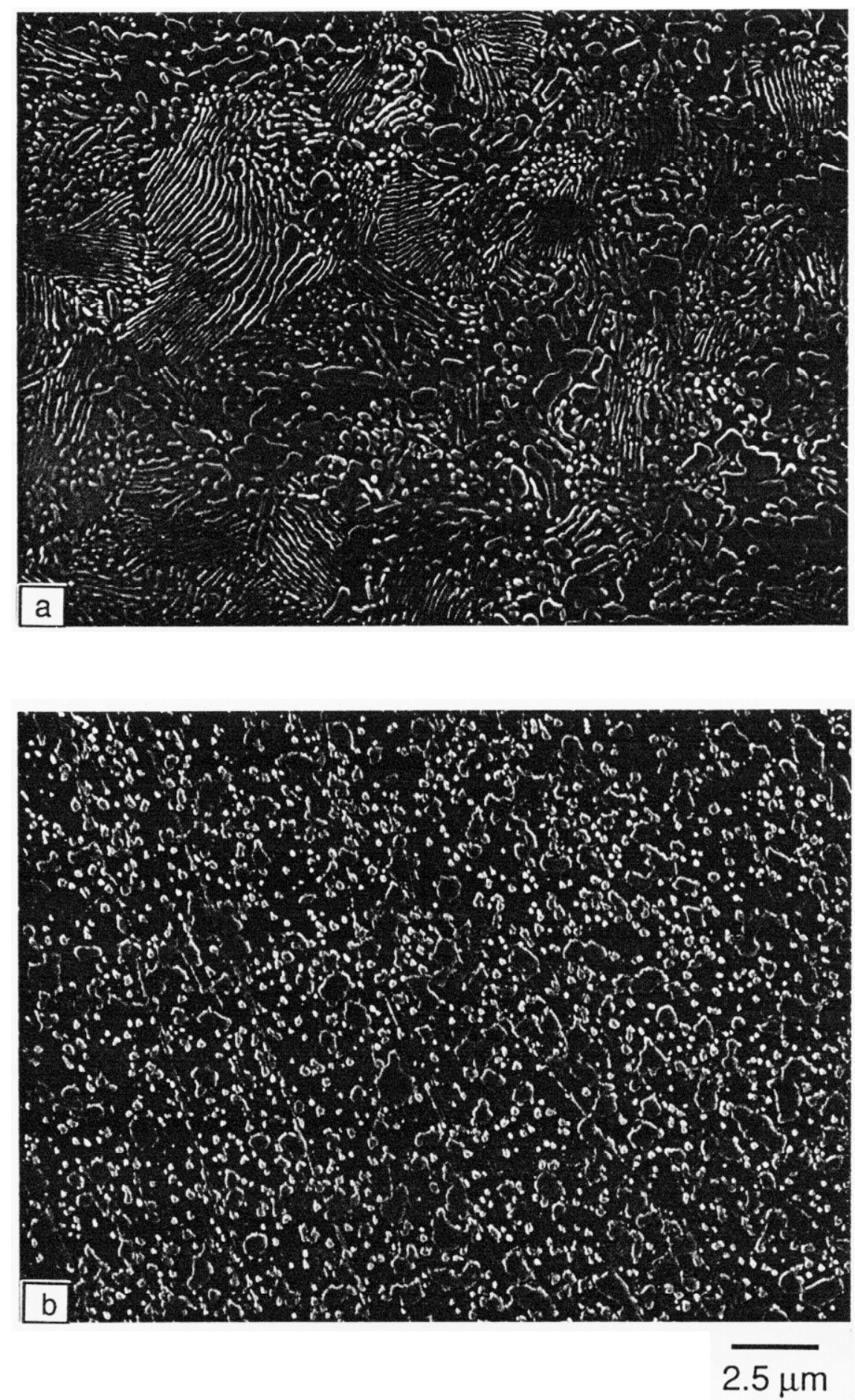

Figure 1 


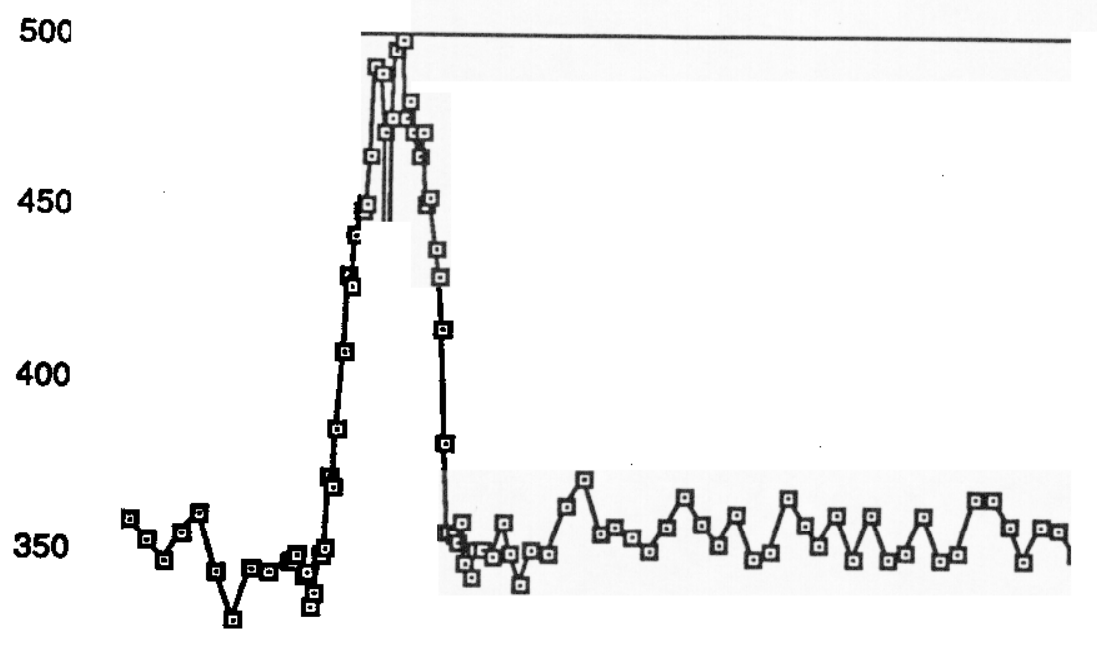

300

$\begin{array}{ll}250 & \\ -4 & -2\end{array}$

a $\begin{array}{lllll}2 & 4 & 6 & 8 & 10\end{array}$

Distance, $\mathrm{mm}$

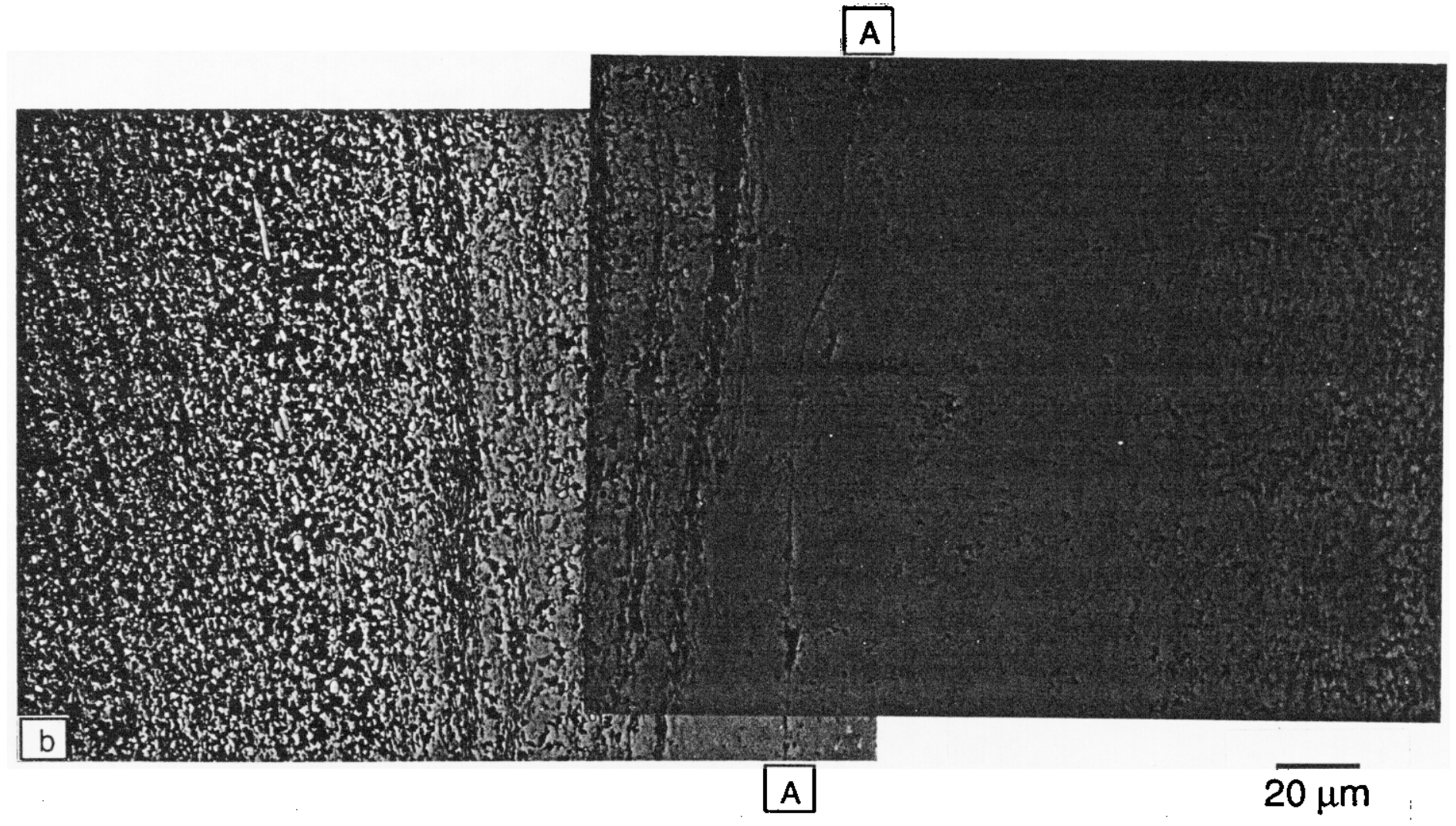

Figure 2 

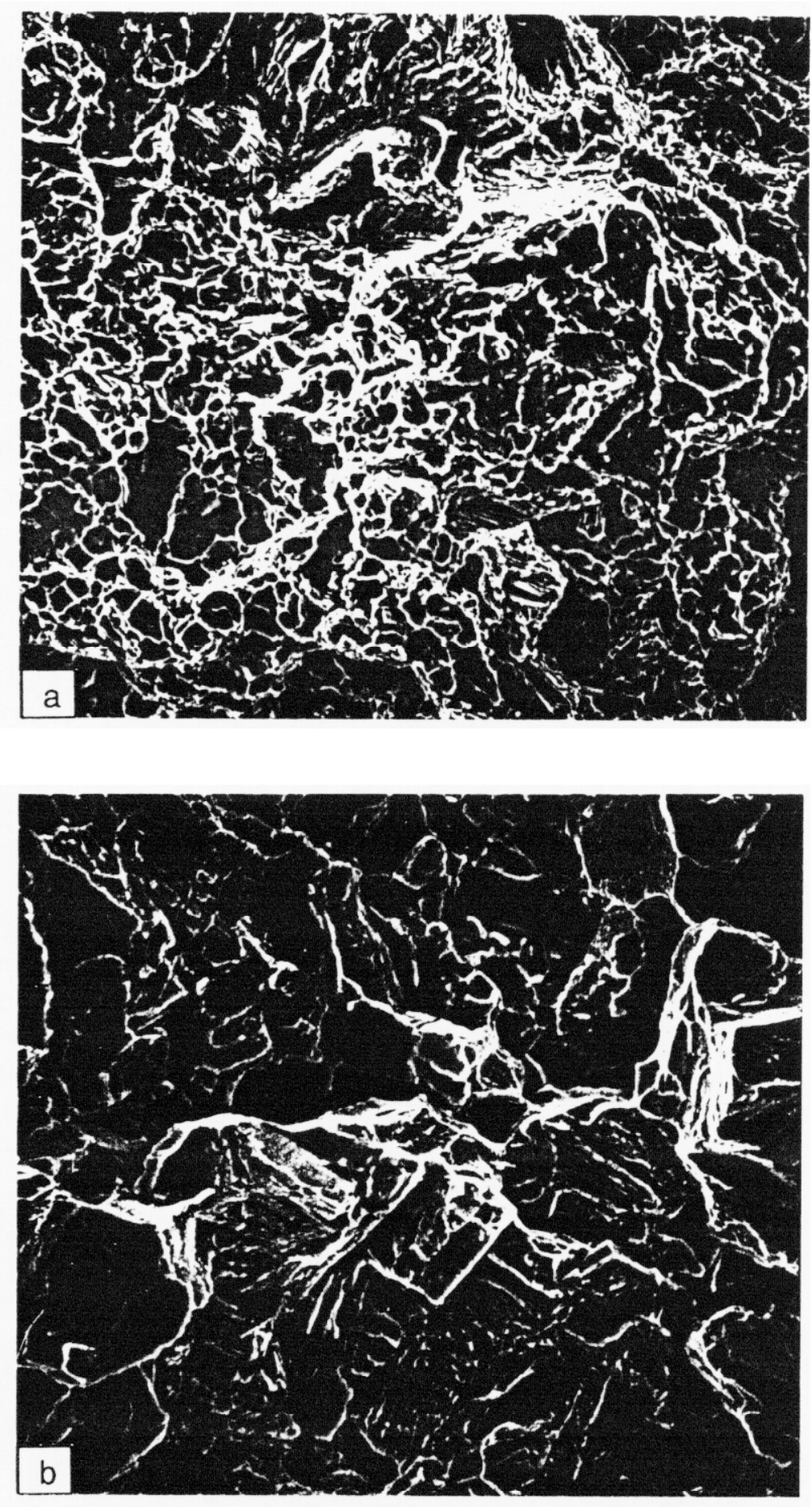

$5 \mu \mathrm{m}$

Figure 3 

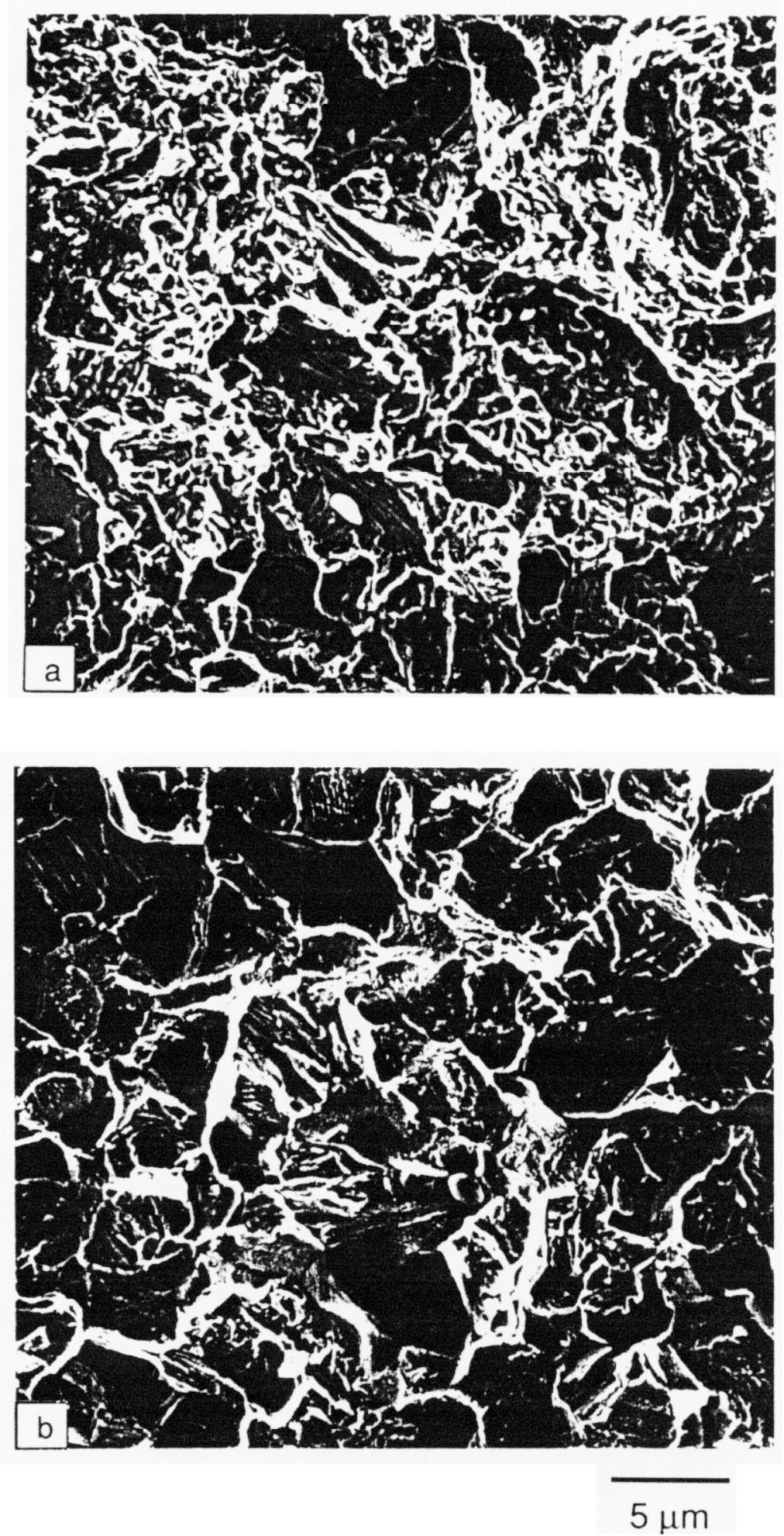

Figure 4 

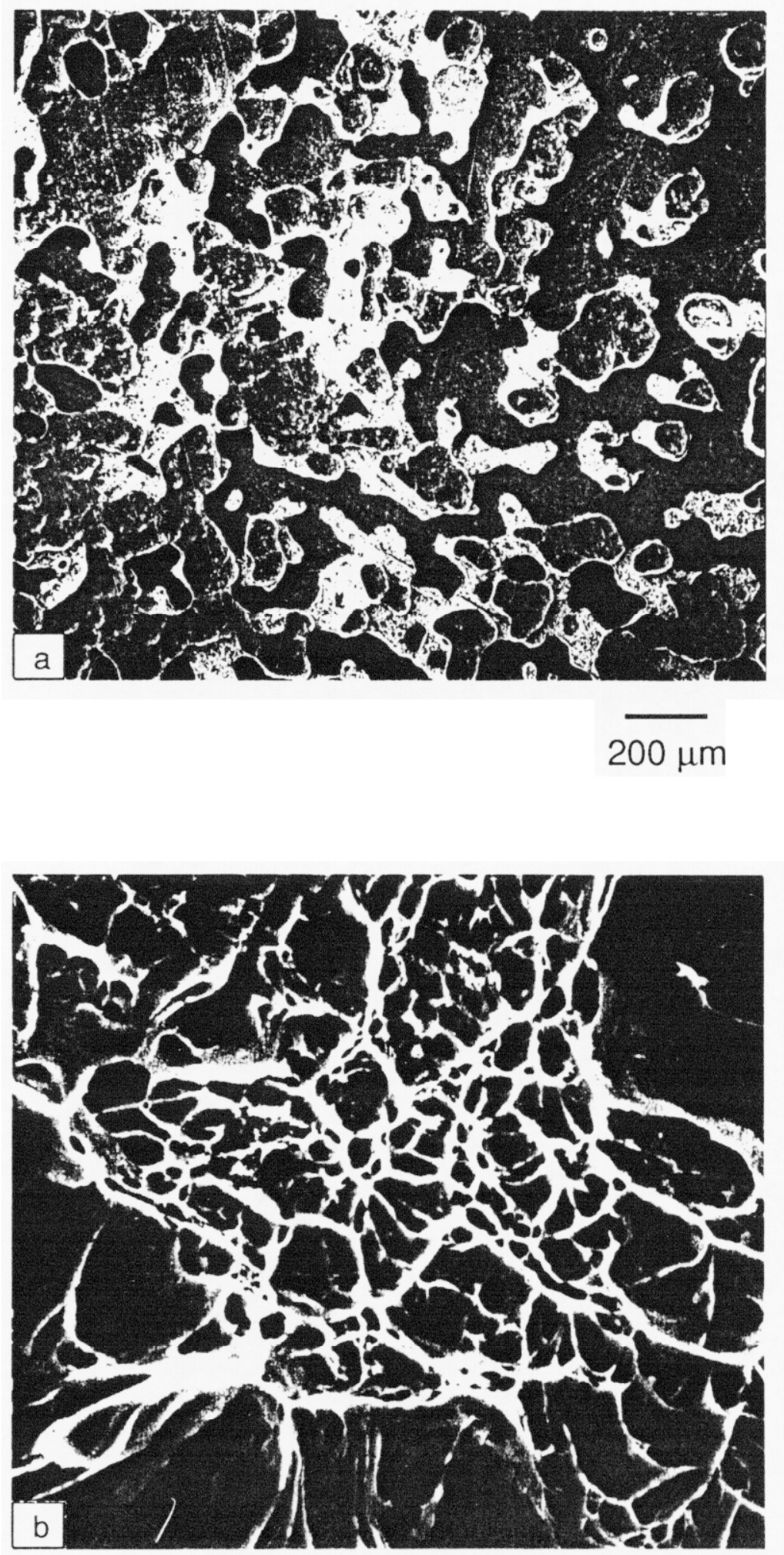

$1 \mu \mathrm{m}$

Figure 5 

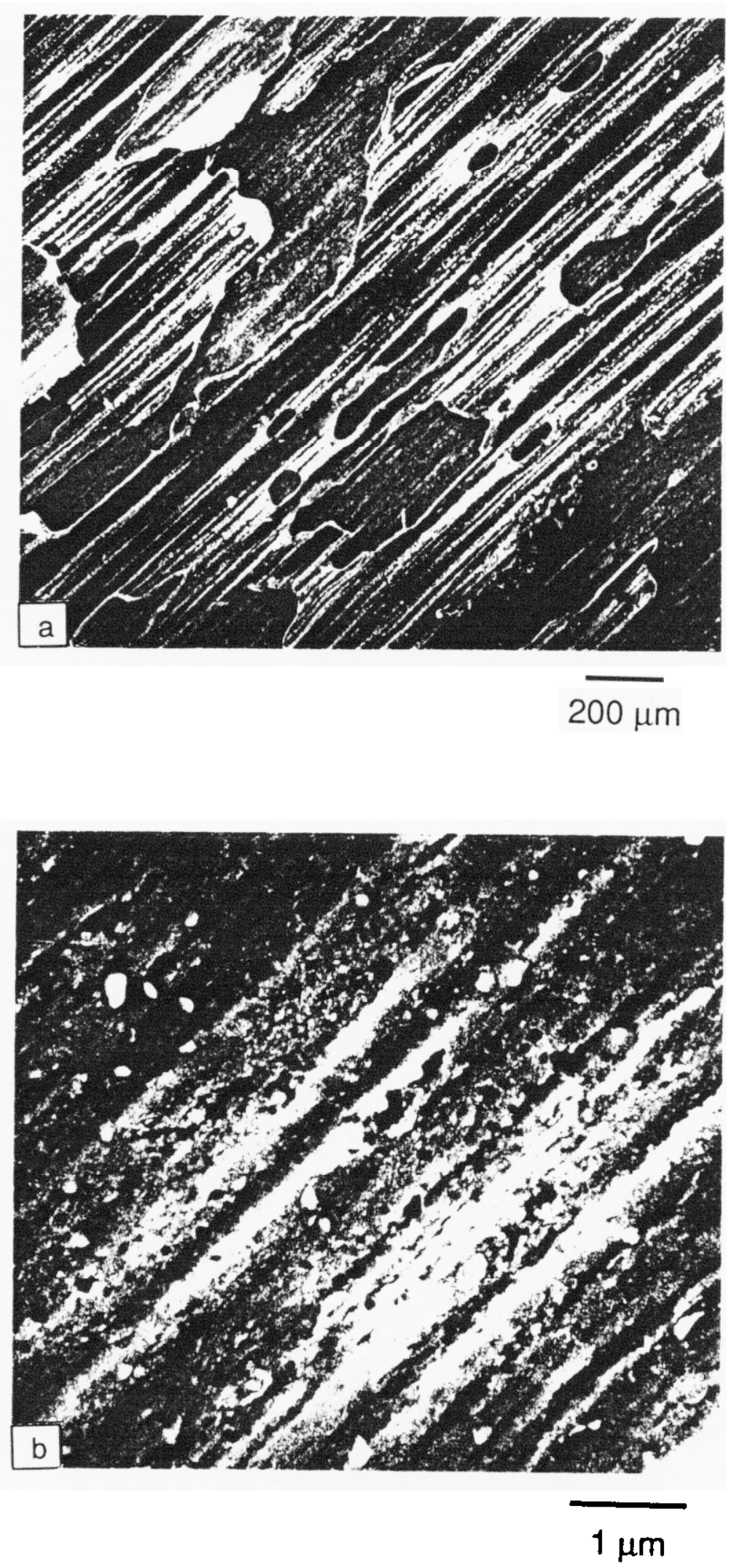

Figure 6 


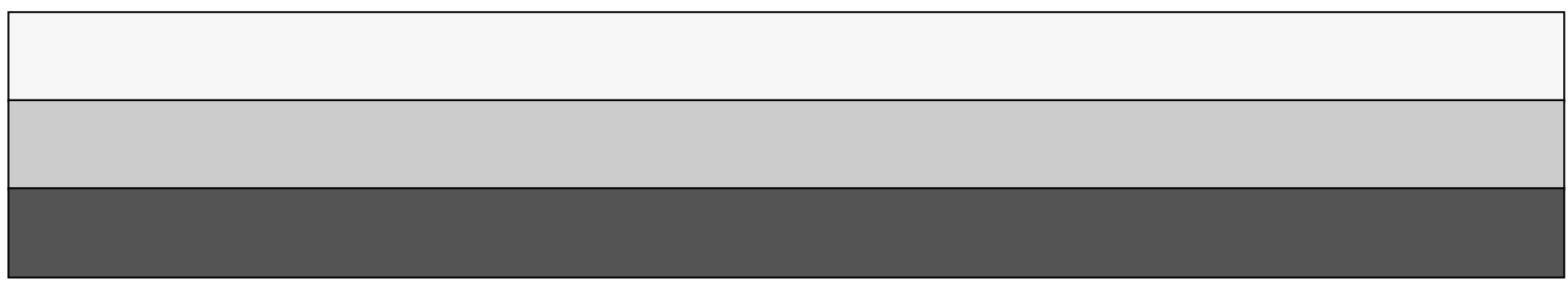

